\title{
COPII and the regulation of protein sorting in mammals
}

\author{
Giulia Zanetti, Kanika Bajaj Pahuja, Sean Studer, Soomin Shim \& Randy Schekman
}

Nat. Cell Biol. 14, 20-28 (2012); published online 22 December 2011; corrected after print 6 January 2012

In the version of this review initially published online and in print, the key in figure 2 was incorrect. The grey dots should represent Sec23-24, the blue lines should represent Sec13-31 and the green dots should represent TRAPPI. The correct figure is reproduced below, and this error has been corrected in the HTML and PDF versions of the review.

Figure 2

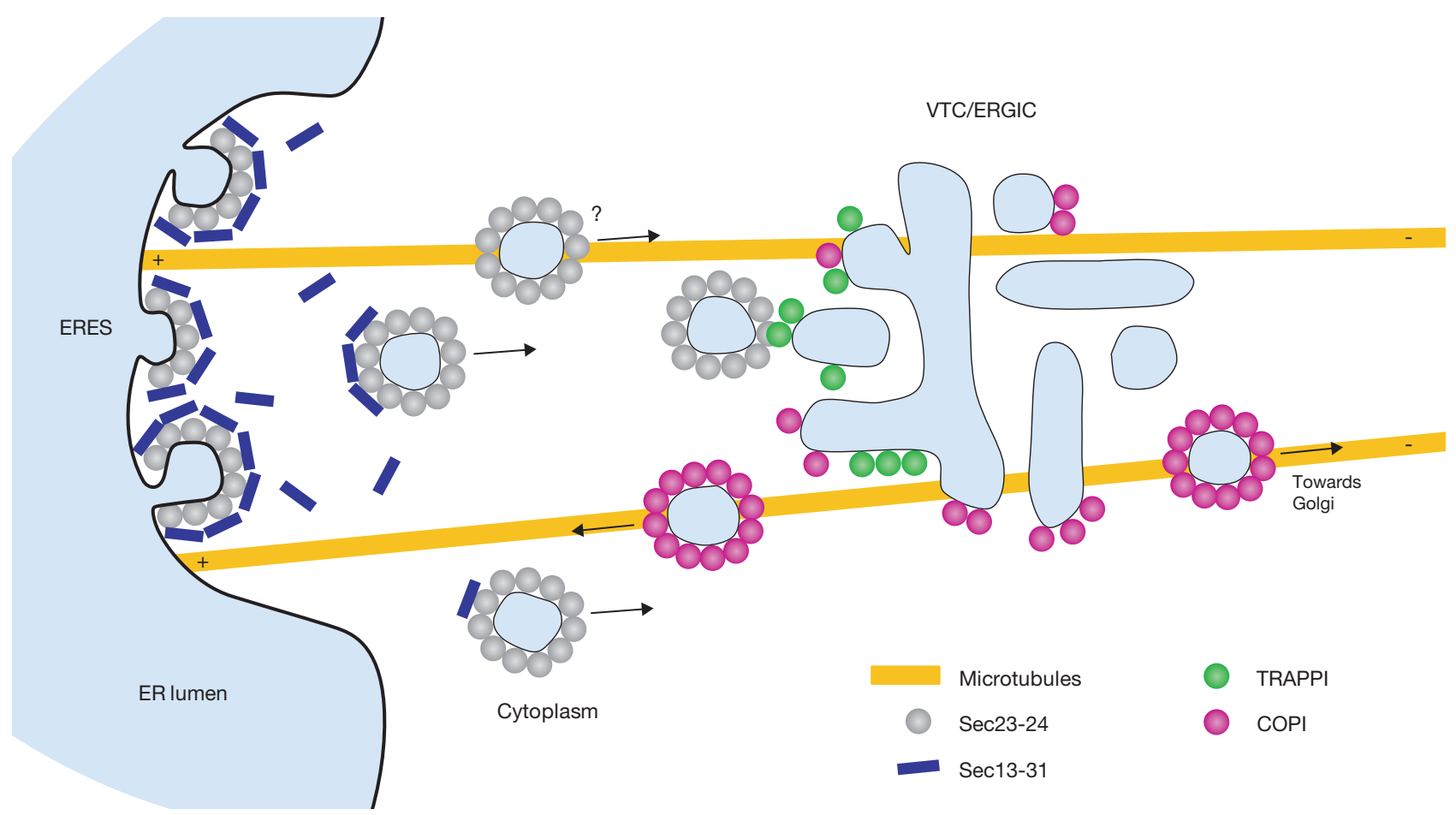

